\title{
ORIGINAL ARTICLE \\ Clinical and demographic profile of traumatic spinal cord injury: a mexican hospital-based study
}

\author{
MV Rodríguez-Meza ${ }^{1}$, M Paredes-Cruz ${ }^{2}$, I Grijalva $^{2}$ and D Rojano-Mejía ${ }^{1}$
}

Study design: Review of clinical data.

Objectives: The objective of this study was to describe the clinical and demographical profile of patients with traumatic spinal cord injury (TSCl) admitted to a single center.

Setting: Unidad de Medicina Física y Rehabilitación Centro, México.

Participants Patients with $\mathrm{TSCl}$ attending rehabilitation for the first time.

Intervention Not applicable.

Main measurements Age, gender, educational level, occupational activity, causes of injury, level of injury, neurological level, injury severity and category were recorded.

Results Four hundred and sixty-four clinical files of patients with TSCI were collected. The mean age was $37.9 \pm 15.9$ years; $78.2 \%$ (363/464) were male, basic educational level predominated in 63.6\% (296/464) and 73.1\% (339/464) were employed. A fall was the main mechanism of the injury in $41.6 \%$ (193/464), replacing automobile accidents from the first place. The mean age of persons who suffered falls was $44 \pm 16$ years. Injuries sustained by younger persons were due to violence ( $28.4 \pm 10.1$ years) and the cause of injury associated with male gender was violence. Thoracic level was most often affected (in 56.7\%, 263/464) and neurological level C4 in $13.4 \%$ (62/464). In regard to the extent of the injury, lesions classified as American Spinal Injury Association A predominated (56.2\%, $261 / 464)$ as with complete paraplegia in $43.3 \%(201 / 464)$.

Conclusions The mean age of our patients was 37 years. Men are affected in a higher proportion. Our population has $<9$ years of study. Physical labor was the usual pre-injury activity. The main mechanism of injury was falls. Thoracic spine was the most affected. Spinal Cord (2016) 54, 266-269; doi:10.1038/sc.2015.164; published online 20 October 2015

\section{INTRODUCTION}

Traumatic spinal cord injury (TSCI) is one of the most devastating lesions that results in a profound disability. TSCI alters the previous lifestyle of the person who experiences the injury, causing a high biosocial and economic impact both in the short- and long-term in young persons during the productive age. ${ }^{1}$

Studies in other countries have been performed to identify the main epidemiological characteristics of patients with TSCI, with special interest in age, gender, cause of injury, extent of injury, neurological level, injury severity and category, which vary according to the social and demographic determinants in each country and to the method used to obtain information. Despite these differences, owing to the increase in the proportion of older adults ${ }^{2}$ and the greater participation of females in activities previously considered as male dominated, changes have arisen worldwide in the demographic characteristics of the patient with SCI. ${ }^{3,4}$

In a systematic review that analyzed the epidemiological characteristics of patients with TSCI in developed countries, it was found that male gender predominated. The average age at presentation was 32.4 years. The main cause of TSCI was automobile accidents followed by falls. Complete injuries and paraplegia predominated. ${ }^{4}$ However, other countries have reported changes such as a reduction in the male/ female proportion ${ }^{5-8}$ and an increase in the age at presentation, ${ }^{8}$ as well as in the cause of injury (predominantly falls), and the categorization of the lesion (predominantly tetraplegia). ${ }^{1,5,9,10}$

In Mexico, there is currently no information about the epidemiological characteristics of patients with TSCI, although determining these characteristics would allow the identification of vulnerable groups and establishment of measures and preventive initiatives to reduce the presentation of new cases. ${ }^{5}$ Therefore, the objective of the present study was to describe the clinical and demographical profile of patients with TSCI from 2006 to 2013, admitted to a single center.

\section{MATERIALS AND METHODS}

A review of clinical data was performed. Medical records were obtained from patients with a diagnosis of TSCI at the Unidad de Medicina Física y Rehabilitación Centro during the period from August 2006 to July 2013. Unidad de Medicina Física y Rehabilitación Centro is a national referral rehabilitation center of the Instituto Mexicano del Seguro Social that offers comprehensive treatment to patients with TSCI in both acute and secundary stages; the multidisciplinary team comprises medical specialists in

${ }^{1}$ Coordinación Clínica de Educación e Investigación en Salud, Unidad de Medicina Física y Rehabilitación Centro, Unidad Médica de Alta Especialidad, Hospital de Traumatología y Ortopedia 'Lomas Verdes', Instituto Mexicano del Seguro Social, D.F., México and 2Unidad de Investigación en Enfermedades Neurológicas, Unidad Médica de Alta Especialidad, 'Hospital de Especialidades Centro Médico Nacional Siglo XXI' IMSS, Instituto Mexicano del Seguro Social, D.F., México

Correspondence: Dr D Rojano-Mejia, Coordinación Clínica de Educación e Investigación en Salud, Unidad de Medicina Física y Rehabilitación Centro, Unidad Médica de Alta Especialidad, Hospital de Traumatología y Ortopedia 'Lomas Verdes', Instituto Mexicano del Seguro Social, Villalongín No. 117, Col. San Rafael, Delegación Cuauhtémoc, C.P: 06500 México, DF, México.

E-mail: rojanodavid@gmail.com

Received 29 July 2014; revised 27 June 2015; accepted 30 August 2015; published online 20 October 2015 
rehabilitation, urology, cardiology, internal medicine, rehabilitation nurses, physical therapists, occupational therapists, dieticians and social workers. Data such as age, gender, educational level, occupational activity, cause of injury, level of lesion, neurological level, injury severity and category were recorded.

\section{Educational level}

Educational level was classified in three groups according to the number of years of study: $0-9,10-12$ and $>12$ years of education.

\section{Work activity}

Work activity was described as follows: actively working were those persons who, at the time of injury, were performing some type of compensated work and who, in turn, were divided into the following: moderate work activity described as activities that require moderate to intense physical effort (laborers, farmers and stevedores) and those who perform light physical labor (administrative work). No work activity applied to pensioned, retired and unemployed persons, housewives and students.

\section{Cause of injury}

Causes of injury were classified as follows: automobile accidents including accidents that occurred while the subjects were traveling in a vehicle or were injured as pedestrians; falls, including falls from one's own height, buildings and trees; violence, including gunshot wounds, knife wounds and aggressions by others; sports, including activities such as swimming, diving and football; and others, including injuries caused by burns, forced traction of the spine and crushing lesions.

\section{Level of the lesion}

Cervical, thoracic, lumbar and sacral levels were considered.

\section{Neurological level and severity of the lesion}

These were defined using the international standards of the American Spinal Injury Association. ${ }^{11}$

Neurological level. The most caudal segment of the spinal cord with normal sensorial and motor function on both sides of the body

Severity of the lesion. Degree or extent of neurological lesion categorized as complete or incomplete.

\section{Categorization of the lesion}

Tetraplegia and paraplegia were considered:

- Tetraplegia: alteration or loss of motor and/or sensory function in the cervical segments of the spinal cord caused by damage to the neural elements within the spinal canal.

- Paraplegia - alteration or loss of motor and/or sensory function in the thoracic, lumbar or sacral segments of the spinal cord due to damage by neural elements within the spinal canal.

\section{Statistical analysis}

Descriptive statistics for qualitative variables and absolute and relative frequencies were obtained. For variables of age, mean and s.d. were used. For inferential statistics, to compare differences between gender by cause of injury, we used $\chi^{2}$-test. To compare differences between mean age by cause of injury, one-way analysis of variance was used; $P<0.05$ was considered statistically significant.

\section{RESULTS}

Data from 464 clinical files of patients with TSCI were collected. The following information was recorded. Mean age was 37.9 years; $78.2 \%$ of the cases were male. More than half of our patients have $<9$ years of study and nearly $90 \%$ have $<12$ years of study. Employed persons represented $73.1 \%$ and more than a third of these people had a job that required heavy physical activity. Falls were the main cause of injuries in $41.6 \%$ of cases followed by automobile accident (Table 1).

In regard to the cause of injury associated with age, falls presented in persons with a mean age of 44 years in contrast to the category of violent acts and sports, which presented in younger persons, 28.4 and 30.4 years, respectively, with the difference being statistically significant $(P=0.01$; Table 2).

The cause of injury associated with gender showed a predominance of falls in both groups followed by automobile accidents; however, violent acts were significantly less common in females (Table 3).

Table 1 General characteristics of the study population $(N=464)$

\begin{tabular}{|c|c|}
\hline Variable & $\begin{array}{c}\text { Total } \\
\text { Mean士s.d., n (\%) }\end{array}$ \\
\hline Age, years & $37.9 \pm 15.9$ \\
\hline Gender, male & $363(78.2)$ \\
\hline Male/female proportion & $3.5 / 1$ \\
\hline \multicolumn{2}{|l|}{ Educactional level } \\
\hline $0-9$ years & $296(63.6)$ \\
\hline 10-12 Years & $121(26.1)$ \\
\hline$>12$ Years & $47(10.1)$ \\
\hline \multicolumn{2}{|l|}{ Occupation } \\
\hline Employed & $339(73.1)$ \\
\hline Light physical activity & $203(59.8)$ \\
\hline Moderate/heavy physical activity & $136(40.1)$ \\
\hline Unemployed & 125 (26.9) \\
\hline \multicolumn{2}{|l|}{ Cause of injury } \\
\hline Falls & $193(41.6)$ \\
\hline Automobile accident & $168(36.2)$ \\
\hline Violence & $61(13.1)$ \\
\hline Sports related & $13(2.8)$ \\
\hline Others & $29(6.2)$ \\
\hline
\end{tabular}

Table 2 Cause of injury associated with age

\begin{tabular}{lc}
\hline Cause of injury & Mean \pm s.d. \\
\hline Automobile accidents & $33.8 \pm 14.6$ \\
Falls & $44 \pm 16$ \\
Violence & $28.4 \pm 10.1$ \\
Sports & $30.4 \pm 12.2$ \\
Others & $43.7 \pm 15.9$ \\
\hline
\end{tabular}

Table 3 Cause of injury associated with gender

\begin{tabular}{lccc}
\hline $\begin{array}{l}\text { Cause of injury } \\
\mathrm{n}(\%)\end{array}$ & $\begin{array}{c}\text { Male } \\
(\mathrm{n}=363)\end{array}$ & $\begin{array}{c}\text { Female } \\
(\mathrm{n}=101)\end{array}$ & $\begin{array}{c}\text { Total } \\
(\mathrm{n}=464)\end{array}$ \\
\hline Automobile accident & $124(34.2 \%)$ & $44(43.6 \%)$ & $168(36.2 \%)$ \\
Falls & $146(40.2 \%)$ & $47(46.5 \%)$ & $193(41.6 \%)$ \\
Violence & $57(15.7 \%)$ & $4(4.0 \%)^{\mathrm{a}}$ & $61(13.1 \%)$ \\
Sports & $13(3.6 \%)$ & 0 & $13(2.8 \%)$ \\
Others & $23(6.3 \%)$ & $6(5.9 \%)$ & $29(6.2 \%)$ \\
\hline
\end{tabular}

a tatistically significant, value of $P<0.05$. 
Table 4 Level, extent and categorization of the injury

\begin{tabular}{lr}
\hline Variable & $\begin{array}{c}\text { Total } \\
(\mathrm{n}=464)\end{array}$ \\
\hline Segment affected & \\
Cervical, $n(\%)$ & $165(35.6 \%)$ \\
Thoracic, $n(\%)$ & $263(56.7 \%)$ \\
Lumbar, $n(\%)$ & $30(6.5 \%)$ \\
Sacral, $n$ (\%) & $6(1.3 \%)$ \\
& \\
ASIA & \\
A, $n(\%)$ & $261(56.2 \%)$ \\
B, $n(\%)$ & $61(13.1 \%)$ \\
C, $n(\%)$ & $104(22.4 \%)$ \\
D, $n$ (\%) & $38(8.2 \%)$ \\
Categorization of the lesión & \\
Complete paraplegia, $n(\%)$ & \\
Incomplete paraplegia, $n$ (\%) & $201(43.3 \%)$ \\
Complete tetraplegia, $n(\%)$ & $100(21.6 \%)$ \\
Incomplete tetraplegia, $n(\%)$ & $60(12.9 \%)$ \\
\hline
\end{tabular}

Abbreviation: ASIA, American Spinal Injury Association.

The most frequent lesions were thoracic in $56.7 \%$ followed by cervical lesions in $35.6 \%$ (Table 4). The most affected neurological level was C4 followed by C5 and T12. There was a predominance of complete lesions, American Spinal Injury Association A, followed by American Spinal Injury Association C. The main affectation was complete paraplegia $43.3 \%$, followed by incomplete tetraplegia, $22.2 \%$ (Table 4).

\section{DISCUSSION}

The present study explores the demographic characteristics, cause of injury and clinical conditions of patients with TSCI, who received physical therapy and rehabilitation for the first time in a specialized hospital unit after being injured in an accident. Patients were transferred from other hospitals in Mexico City and neighboring states after having resolved the primary health problems immediately after the accident, which included spine surgery and intensive therapy. Although there are some Mexican studies, the present study, by including almost 500 patients with $>7$ years of SCI patient data, allows a clearer characterization of SCI patients in our population over time.

The mean age of patients in the present study was similar to that reported in the literature, 37.9 years; $5,6,10,12-14$ however, this differs from data for Mexico previously published in 2008, ${ }^{15}$ where the mean age was estimated at 33.6 years $(P=0.009)$, reflecting a trend in the increasing age of presentation in patients with TSCI as demonstrated in other studies worldwide. ${ }^{5,9,12,16,17}$ This may be due to the increase in the proportion of persons $>60$ years of age.

Male/female ratio was $3: 5$, which is similar to that previously reported in Mexico and in other countries; $;^{1,5,13,18,19}$ however, this differs with the global tendency favoring a reduction in the male/ female proportion. ${ }^{6,20,21}$

In México, $63 \%$ of the population have low education level (less than 9 years) and the employment rate for this population is $64 \%$, whereas the employment rate for those with a higher education (over 12 years) is nearly $80 \% .^{22}$ This coincides with our sample of patients with SCI.
This is important, as education has been regarded as a key determinant of the return to work in patients with SCI, ${ }^{14,17}$ a study found that patients with SCI schooling for 8 to 13 years have an odds ratio of 3.27 in comparison with those who have $<8$ years, and with an average of 13 years the odds ratio reaches $13.26 .{ }^{17}$

A lower education is associated with jobs that demand an excess of physical activity, and when it comes to SCI patients their physical capacity is limited and becomes evident with aging when compared with the rest of the population. ${ }^{23}$

Employed persons predominated $(73 \%)$ as previously reported for Mexico $^{18}$ and more than a third of these people had a job that required heavy physical activity. This implies a significant effort to reincorporate into the workforce the greatest number of subjects possible, in order to achieve an integral rehabilitation, improving quality of life (QOL) and reducing costs and impact of disability.

The job reincorporation in patients with SCI is the main goal of rehabilitation programs, because this is equivalent to social reintegration, which has a psychological, social and economic impact on QOL. ${ }^{23}$

Unfortunately, one of the major limitations of our patients to return to work is the low education rate coupled with health system, which, similar to other countries, offer economic compensation ${ }^{20}$ more than a job training, or the creation of strategies to keep the job, which promotes disinterest to return to work and improve the QOL. ${ }^{18}$

Currently, there are few studies that evaluate the QOL and functionality in developing countries; however, it has been shown that economic status and education level are factors that strongly correlate with a higher QOL, social participation, mental health improvement, lower risk of developing pain and fewer comorbidities. ${ }^{17}$

Therefore, it is important to develop multidisciplinary strategies to promote and encourage the training of patients with SCI to favor their job reincorporation, as well as to promote continuous learning in order to increase QOL in our population with SCI.

Currently, a few studies are analyzing the QOL and functionality in developing countries; ${ }^{24}$ however, it has been shown that the economic status and the level of education are important factors associated with increased QOL, social participation, better mental health, less pain and fewer comorbidities. ${ }^{17,20,25}$ This is due to the economic difficulties worsen the perception of the health of individuals by limiting access to services, generating psychological stress.

Therefore, it is important to develop multidisciplinary strategies to promote and encourage the training of patients with SCI to return to work and promote continuous learning to increase the QOL of patients with spinal cord injuries in our population.

In regard to the cause of injury, automobile accidents predominated in other studies, ${ }^{1,5,9,20}$ nevertheless, in recent years, falls have been the primary cause of TSCI in the Mexican population. This change is also reflected in other studies $5,13,19$ and may be explained by the increase in the proportion of persons $>60$ years of age, who present SCI associated with falls. ${ }^{5,9,12,16}$ In regard to the cause of injury associated by gender, violence and sports predominate among males; in females, automobile accidents are the predominate cause.

In regard to cause of injury associated with age, the results are similar to those reported in other studies, ${ }^{1,5,7}$ finding younger populations more susceptible for presenting secondary TSCI due to automobile accidents, violence and sports, which differs significantly from the mean age of presentation in falls as a cause of TSCI.

In the study sample, thoracic lesions predominated. This coincides with that previously reported in Mexico ${ }^{18}$ and in other countries, 5,19 
unlike that reported in other regions, especially in developed countries where there has been an increase in the presentation of affected cervical segments conditioning incomplete tetraplegia. ${ }^{1,6,7,9}$ The above is probably due to rapid, efficient access to medical services during critical periods, which increases the probability of survival for patients with cervical lesions.

The most frequent affliction was complete lesion, which agrees with previous publications. ${ }^{7,13}$ However, by combining the segments affected with the American Spinal Injury Association classification, we found that complete and incomplete paraplegia coincide with reports in developing countries. ${ }^{1,6,7,9,17}$ This may be explained by the quality of the care of polytraumatized patients in other countries, which allows survival of patients with the most severe TSCI.

\section{Study limitations}

The limitations of the study are those characteristic of a descriptive study. In addition, data were included only for patients who survived and who were then referred for rehabilitative therapy. Although the unit is a national referral center, patients do not always attend rehabilitation due to economic reasons. In addition, data from patients who died at the time of the accident were not considered. This may underestimate the number of patients with injuries due to automobile accidents and overestimate the number of patients injured as a result of falls. These patients are medically more stable than patients with multiple contusions secondary to automobile accidents.

\section{CONCLUSIONS}

The mean age of our patients was 37 years. Men are affected in a higher proportion. Our population has a basic level of education. Occupational involvement was the main cause of injury. The main mechanism of injury was falls. The most affected segment was the thoracic spine and the most frequent neurological level was C4. Complete paraplegia predominated.

\section{DATA ARCHIVING}

There were no data to deposit.

\section{CONFLICT OF INTEREST}

The authors declare no conflict of interest.

\section{ACKNOWLEDGEMENTS}

We thank Antonio Barrera Cruz (PhD), Medical Programs Coordinator, Division of Clinical Excellence, Instituto Mexicano del Seguro Social, Mexico, for reviewing the article and suggestions in the statistics.
1 van den Berg ME, Castellote JM, Mahillo-Fernandez I, de Pedro-Cuesta J. Incidence of spinal cord injury worldwide: a systematic review. Neuroepidemiology 2010; 34: 184-192 discussion 92.

2 Wong R, Espinoza M, Palloni A. [Mexican older adults with a wide socioeconomic perspective: health and aging]. Salud Publica Mex 2007; 49: S436-S447 Adultos mayores mexicanos en contexto socioeconomico amplio: salud y envejecimiento.

3 Kuhn W, Zach GA, Kochlin P, Urwyler A. Comparison of spinal cord injuries in females and in males, 1979-1981 Basle. Paraplegia 1983; 21: 154-160.

4 Rahimi-Movaghar V, Saadat S, Rasouli MR, Ganji S, Ghahramani M, Zarei MR et al. Prevalence of spinal cord injury in Tehran, Iran. J Spinal Cord Med 2009; 32 428-431.

5 Pickett GE, Campos-Benitez M, Keller JL, Duggal N. Epidemiology of traumatic spinal cord injury in Canada. Spine (Phila Pa 1976) 2006; 31: 799-805.

6 Wyndaele M, Wyndaele JJ. Incidence, prevalence and epidemiology of spinal cord injury: what learns a worldwide literature survey? Spinal Cord 2006; 44: 523-529.

7 Jackson AB, Dijkers M, Devivo MJ, Poczatek RB. A demographic profile of new traumatic spinal cord injuries: change and stability over 30 years. Arch Phys Med Rehabil 2004; 85: 1740-1748.

8 NSCISC The 2012 Annual Stadistic Report. United States 2012 (cited 27 April 2014). Available from https://www.nscisc.uab.edu/PublicDocuments/reports/pdf/2014\%20 NSCISC\%20Annual\%20Statistical\%20Report\%20Complete\%20Public\%20Version.pdf.

$9 \mathrm{Ho}$ CH, Wuermser LA, Priebe MM, Chiodo AE, Scelza WM, Kirshblum SC. Spinal cord injury medicine. 1. Epidemiology and classification. Arch Phys Med Rehabil 2007; 88: S49-S54.

10 O'Connor RJ, Murray PC. Review of spinal cord injuries in Ireland. Spinal Cord 2006; 44: $445-448$.

11 Kirshblum SC, Burns SP, Biering-Sorensen F, Donovan W, Graves DE, Jha A et al. International standards for neurological classification of spinal cord injury (revised 2011). J Spinal Cord Med 2011; 34: 535-546.

12 Ahoniemi E, Alaranta H, Hokkinen EM, Valtonen K, Kautiainen H. Incidence of traumatic spinal cord injuries in Finland over a 30-year period. Spinal Cord 2008; 46 : 781-784.

13 Agarwal P, Upadhyay P, Raja K. A demographic profile of traumatic and non-traumatic spinal injury cases: a hospital-based study from India. Spinal Cord 2007; 45: 597-602.

14 Pagliacci MC, Celani MG, Zampolini M, Spizzichino L, Franceschini M, Baratta S et al. An Italian survey of traumatic spinal cord injury. The Gruppo Italiano Studio Epidemiologico Mielolesioni study. Arch Phys Med Rehabil 2003; 84: 1266-1275.

15 Pérez R, Martín del Campo S, Renán S, Durán S. Aspectos epidemiológicos de la lesión medular de la población del Centro Nacional de Rehabilitación. Revista Mexicana de Medicina Física y Rehabilitación 2008; 20: 74-82.

16 Sekhon LH, Fehlings MG. Epidemiology, demographics, and pathophysiology of acute spinal cord injury. Spine (Phila Pa 1976) 2001; 26: S2-S12.

17 Fekete C, Siegrist J, Reinhardt JD, Brinkhof MW. Is financial hardship associated with reduced health in disability? The case of spinal cord injury in Switzerland. PLOS ONE 2014; 9: e90130.

18 Paul C, Derrett S, McAllister S, Herbison P, Beaver C, Sullivan M. Socioeconomic outcomes following spinal cord injury and the role of no-fault compensation: longitudinal study. Spinal Cord 2013; 51: 919-925.

19 Dahlberg A, Kotila M, Leppanen P, Kautiainen H, Alaranta H. Prevalence of spinal cord injury in Helsinki. Spinal Cord 2005; 43: 47-50.

20 Lidal IB, Huynh TK, Biering-Sorensen F. Return to work following spinal cord injury: a review. Disabil Rehabil 2007; 29: 1341-1375.

21 O'Connor PJ. Prevalence of spinal cord injury in Australia. Spinal Cord 2005; 43: 42-46.

22 OCDE OECD Employment Outlook (cited 2 June 2015). Available from http://www.oecd. org/centrodemexico/estadisticas/.

$23 \mathrm{Ku} \mathrm{JH}$. Health-related quality of life in patients with spinal cord injury: review of the short form 36-health questionnaire survey. Yonsei Med J 2007; 48: 360-370.

24 Gosselin RA, Coppotelli C. A follow-up study of patients with spinal cord injury in Sierra Leone. Int Orthopaed 2005; 29: 330-332.

25 Krause JS, Terza JV, Erten M, Focht KL, Dismuke CE. Prediction of postinjury employment and percentage of time worked after spinal cord injury. Arch Phys Med Rehabil 2012; 93: 373-375. 